\title{
An analysis of the global additive manufacturing response to the COVID-19 pandemic
}

\author{
Maximilian Kunovjanek and Christian Wankmüller \\ Department of Operations, Energy, and Environmental Management, \\ Universitaet Klagenfurt, Klagenfurt, Austria
}

\begin{abstract}
Purpose - The COVID-19 pandemic caused global supply disruptions and shortages that resulted in countries battling over desperately needed (medical) supplies. In this mayhem, additive manufacturing (AM) provided relief to the strained healthcare systems and manufacturing environments by offering an alternative way to rapidly produce desired products. This study sheds light on how AM was used globally in response to the COVID-19 pandemic.

Design/methodology/approach - The study undertakes a systematic and content-centric review of 289 additively manufactured products made in response to the COVID-19 pandemic. Additionally, quantitative frequency-based text mining and various descriptive analyses were applied that support the investigation of the subject under regard.

Findings - Results show that AM was primarily used in the medical domain for the production of standard medical items, such as personal protective equipment (PPE) but also for non-obvious and new applications (e.g. swab simulator, rapid diagnostic kits, etc.). Also, certain paradigm shifts were observed, as the effective move to mass production and the mitigation of problems related to certification and standardization emerged as prominent management prospects. Nevertheless, various obstacles arose and remained in the path of lasting AM success, especially with respect to print quality, raw material supply and technological versatility.

Originality/value - Due to the actuality of the topic under investigation, no comparable study has so far been conducted. The systematic review provides a conclusive and precise foundation for further analysis and subsequent discussions. Additionally, no comparable study mapping such a wide array of different AM products exists today.
\end{abstract}

Keywords 3D-printing, Additive manufacturing, COVID-19, Coronavirus, Medical goods, Supply chain Paper type General review

\section{Introduction}

At the beginning of the year 2020, the world population faced one of its biggest challenges in recent history - the outbreak of a newly discovered coronavirus. This virus, which causes an acute respiratory infection (COVID-19), spread rapidly through the world, resulting in a global pandemic that forced governments to adopt harsh measures to slow down its propagation (Liu et al., 2020). Therefore, social distancing (i.e. avoiding human-to-human contact) became the top priority, leading to the closure of schools, non-essential shops and, in many cases, land borders. While this already created a great impact on the service and manufacturing industry, an extraordinarily high demand for specific medical goods, such as personal protective equipment (PPE) and ventilators further aggravated the disruption of supply chains (Ranney et al., 2020). Established and proven corridors for the transport of goods also began to collapse under the pressure of COVID-19 containment measures. Internationally operating manufacturers had to shut down their plants, as the risk of an

(C) Maximilian Kunovjanek and Christian Wankmüller. Published by Emerald Publishing Limited. This article is published under the Creative Commons Attribution (CC BY 4.0) licence. Anyone may reproduce, distribute, translate and create derivative works of this article (for both commercial and noncommercial purposes), subject to full attribution to the original publication and authors. The full terms of this licence may be seen at http://creativecommons.org/licences/by/4.0/legalcode

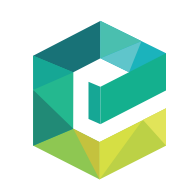

Journal of Manufacturing Technology Management Vol. 32 No. 9, 2021 pp. $75-100$ Emerald Publishing Limited 1741-038X DOI 10.1108/JMTM-07-2020-0263 
JMTM 32,9

unintentional spread of the virus was simply too high, resulting in critical supply shortages all over the globe (Emanuel et al., 2020). Soon, it became apparent that conventional strategies of globalized production and long-distance transportation were unable to satisfy the demand surge for medical items, vital testing equipment and other urgently needed products. At this point, the global additive manufacturing (AM) community stepped up and supported the immediate short-term manufacturing chain.

The process of AM enables goods to be produced directly from computer-aided design files by adding one layer after another, allowing for an unmatched design freedom (Schniederjans, 2017a), resource efficiency (Wohlers, 2019; Kunovjanek and Reiner, 2020), manufacturing flexibility (Eyers et al., 2018) and responsiveness (Zanoni et al., 2019). These benefits had previously attracted attention, as decentralized AM facilitates timely production at the point of need (Li et al., 2017). Nevertheless, AM adoption remains limited (Holzmann et al., 2020; Thomas-Seale et al., 2018). The COVID-19 pandemic was one of the first times the global AM community had an opportunity to prove that the expectations from this manufacturing approach were not too high. With the increasing pressure on supplying critical emergency items, the application of AM technology gained massive momentum. People around the globe initially used AM for various reasons, but with the outbreak of the pandemic, they bundled their capabilities to contribute to the fight against the crisis by printing urgently-needed goods (Cavallo et al., 2020; Cox and Koepsell, 2020). Numerous initiatives were launched to address COVID-19 related supply shortages using AM, which has proven to offer the adaptability and flexibility required. To get a comprehensive overview of how AM was used in response to the pandemic, this paper reviews global AM interventions by eliciting which products were printed where in the world, by which type of organization and through the application of which specific AM technology. With this, we aim at expanding already existing knowledge on traditional application areas of AM and shedding light on novel ones that have not yet been communicated. Aside from this, the study discusses the advantages and challenges that have accompanied AM in the fight against the pandemic. This should not only provide managers and policymakers with valuable insights but also raise the awareness of other organizations and civil society regarding the importance of AM for the manufacturing industry. Therefore, the following research questions $(R Q s)$ were formulated:

$R Q 1$. How was AM used in response to the supply shortages during the COVID-19 pandemic?

RQ2. What challenges and advantages emerged and pertained to AM during the COVID19 pandemic?

To conclusively answer these research questions, we relied on a multi-method research approach based on empirical data. It predominantly revolves around a systematic review of 289 AM products made in response to the COVID-19 pandemic. Additionally, frequency-based text mining and various descriptive analyses were applied.

The article continues with a brief review of the related work focusing on AM during the COVID-19 pandemic (Section 2). Section 3 then describes the study design as well as the applied methodologies. In Section 4, the results of the systematic review and the coding process are analyzed. Following that, Section 5 includes a discussion of the results with a focus on assessing remaining and novel prospects as well as challenges concerning the application of AM. Section 6 concludes the article with a brief summary and by pointing out the main contributions and shortcomings of this article, as well as potential future research avenues. 


\section{Related work}

The benefits of AM have recently shifted into the focus of humanitarian organizations, as the technology enables more effective and efficient disaster response and long-term recovery applications. Especially the capability of AM to produce replacement parts on-site in remote areas that are unreachable by traditional modes of supply facilitates the availability of scarce resources. In this regard, studies by La Torre et al. (2016) and Muir and Haddud (2017) have pointed out that AM for maintenance processes greatly increases the organizations' performance and flexibility. With the swift production of spare parts and other urgently needed equipment, the technology mitigates delays in the supply chain and fosters the rapid availability of required items. Moreover, AM can help to achieve cost reductions, as no further costs for expensive last-mile transportation are incurred (Tatham et al., 2015). Further, AM offers the opportunity to react appropriately to variable and difficult-to-forecast product demand (den Boer et al., 2020). AM is a vital approach to overcome disaster-related supply chain disruptions and manufacturing bottlenecks - as they occurred during the COVID-19 pandemic. Here, the international AM industry stepped in and provided support to relax the global shortage of PPE, connectors to breathing devices, face shields, COVID-19 specimen collection kits and medications (Ishack and Lipner, 2020; Lai et al., 2020; Maracaja et al., 2020). The available literature up to now mostly comprises technical reports and feasibility studies that aim at accelerating scientifically driven applications of AM in the COVID-19 context. For example, technical notes to convert snorkeling masks into emergency CPAP (continuous positive airway pressure) devices were communicated by Cavallo et al. (2020) and a 3D-printed swab for diagnostic testing was proposed by Ford et al. (2020) and Sun et al. (2020). Another patient-related innovative application of AM is discussed by Sedigh et al. (2020). The authors explain how to use AM to treat injuries with the objective to reduce direct human interaction.

Due to the criticality of the supply shortages of urgently needed PPE, research dedicated special attention to that matter. Salmi et al. (2020) presented a study analyzing the number and costs of parts that can be produced by a single AM machine within a given time window. Scaling it up allowed them to find out the potentials of the global AM community to support the fight against the pandemic. Their quantitative comparison reveals that most potential healthcare products are those that have a high productivity with a single set of equipment and widespread availability of equipment in the market. Erickson et al. (2020) illustrated how AM contributed to alleviating critical shortages of essential PPE for healthcare workers. They retrofitted unused surgical helmet systems by means of AM to transform them into PPE. Choong et al. (2020) stated that AM offers the unique chance to balance demand or supply shortages during the pandemic and suggest several goods to be manufactured with this technology (e.g. medical and testing devices, emergency dwellings etc.). They conclude their short paper with a brief outlook on how AM and its increased usage will impact the future design of international supply chains. A letter to the editor by Flanagan and Ballard (2020) discusses the role of AM in the production of PPE during the COVID-19 pandemic. The authors point to the fact that on a global scale, AM enthusiasts and AM laboratories are key drivers for overcoming critical supply shortages. They underline the relevance of the worldwide AM community to support the manufacturing and supply of PPE in the collective fight against the pandemic. The importance of AM to relax international supply shortages of PPE (e.g. face shields and face masks) was additionally underlined by Sinha et al. (2020). They concluded that distributed fabrication through AM helps to remove bottlenecks at the point of need.

Design options for 3D-printed face shields were proposed by Shokrani et al. (2020), Amin et al. (2020), Singh (2020) and Westphal et al. (2020), while 3D-printed face masks were introduced by Agarwal et al. (2020), Lück et al. (2020), Cortes (2020) and Swennen et al. (2020). The latter considered reusable polyamide composite components as raw material input for the printing process but pending leakage and virologic testing prevent the clinical usage of the protective equipment. Corresponding workflows that include detailed descriptions of key-aspects were
Global AM response to COVID-19 
JMTM 32,9

78

elaborated by Gomes et al. (2020), Marconi et al. (2020) and Meglioli et al. (2020). Zuniga and Cortes (2020) analyzed the potentials of AM using antimicrobial polymers for the development of critical items. Following latest publications, the authors highlight the biocidal effects of copper nanocomposites and their antimicrobial behavior that allows inactivating the virus on surfaces of AM goods. Attaran (2020) presents a general overview about current technologies, trends, key benefits and advantages of AM and concluded with a brief overview about COVID19 related insights. Here, the author pointed to the various organizations (e.g. governments, universities, AM firms, automakers, etc.) that stepped in to provide urgently needed materials. Advincula et al. (2020) pointed out the variety of PPE that was produced during the COVID-19 pandemic by selected organizations and universities. In their prospective article, the authors additionally underlined the importance of validation and testing of properties of materials used to additively manufacture medical items. Another study by Belhouideg (2020) gives further insights on how to manage the production of PPE and ventilator systems. Vordos et al. (2020) analyzed how AM in combination with social media was used to tackle worldwide shortages of PPE. They found out that the social media channels Facebook and Twitter were mostly used to distribute design files for the AM of PPE. Mahr and Dickel (2020) detailed on how AM was used during the COVID-19 pandemic by private users in light of intellectual property rights. The reaction of international stakeholders (i.e. policymakers and industries) to private printing engagement was also discussed in their article.

To the best of our knowledge, no other study dedicates such exclusive attention to AM in the context of the COVID-19 pandemic as presented in this paper. It is a first of its kind study that presents a comprehensive overview about the international AM reaction as an answer to the far-reaching impacts of the COVID-19 pandemic. With this investigation, the knowledge base about the challenges and advantages of AM usage are enriched by latest observations from the technologies' application in the COVID-19 context.

\section{Study design and methodology}

To obtain a clear picture of how the global AM community reacted to the challenges arising with the COVID-19 pandemic, we sought to analyze which products were printed where in the world, by which type of organization and through the application of which specific AM technology. In doing so, we started out with data gathering and compiled a non-exhaustive list of $289 \mathrm{AM}$ products made in response to the COVID-19 pandemic. In addition, we also analyzed 173 media articles through simple text mining in order to create an initial understanding concerning this matter. Then a coding framework was developed based on the existing academic literature and the data under regard. After that the collected material was coded, which is the process of analyzing qualitative data by extracting information from text and other primary or secondary sources. Finally, the generated results served for a discussion on the topic, to derive theoretical as well as practical implications. In the following, we start by setting the methodological background of the applied multi-method research approach. During the entire research process, we followed the strict methodological standards of systematic reviewing and content analysis, a process map of which can be found in Figure 1.

Figure 1.

Process map of the applied research methodology

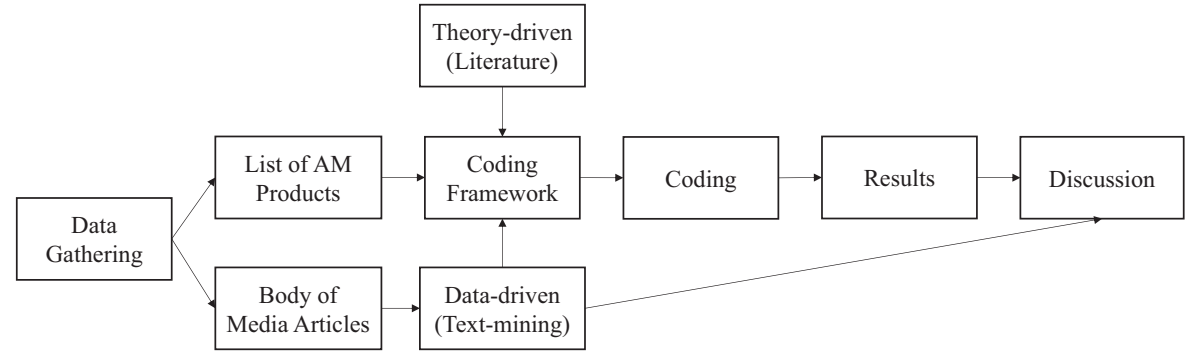




\subsection{Data gathering}

For answering the research questions of this study, secondary data available online on homepages, in company reports, press releases and media articles were considered (Ritchie et al., 2013). Using secondary data offers the clear advantage of faster information gathering compared to the time-consuming collection of primary data (Cowton, 1998). Especially in the context of the COVID-19 pandemic and associated containment measures hampering primary data collection, the use of secondary data can be a viable option. According to Karlsson (2016), a systematic search for relevant data has to be rigorous and transparent. It starts with the identification of relevant search terms from which a search string is composed. In our case, we analyzed the response of the global AM community to the COVID-19 pandemic, therefore both terms "Additive Manufacturing" and its most common synonym " $3 D$-Printing" formed the starting point of the search string. They were joined with the obvious search term "COVID-19" and the relevant corresponding alternatives "Corona Virus" and "SARS-CoV-2". To enhance the global reach of our analysis and to avoid limiting our search to the most prominent results we enhanced the search string with different country names (i.e. "Country Name"). This also served to reduce the personalization bias of online search engines, an issue that was pointed out by Piasecki et al. (2018) when using search engines for scientific research. Through this systematic search process, two sets of data were compiled; a non-exhaustive list of $289 \mathrm{AM}$ products manufactured in response to the COVID-19 pandemic and a body of 173 media articles focusing on the same matter. The search was conducted in June 2020 and the inclusion criteria and corresponding descriptions for the two data sets can be seen in Table 1.

\begin{tabular}{ll} 
Criteria & Description \\
\hline $\begin{array}{l}\text { Non-exhaustive list of } \\
\text { Additive }\end{array}$ & The products in response to COVID-19 \\
manufacturing & The product had to be manufactured in response to or with a direct connection to the \\
COVID-19 & $\begin{array}{l}\text { COVID-19 pandemic } \\
\text { Eistinguishable } \\
\text { product }\end{array}$
\end{tabular}

Body of media articles about AM response to COVID-19

Additive The article had to focus on AM.

manufacturing

COVID-19 The article had to focus on COVID-19

English All articles had to be written in the English language

Global AM response to COVID-19

Table 1.

Inclusion criteria for systematic review

\subsection{Text mining}

Text mining is a well-established process for the systematic extraction of information from unstructured bodies of text. Several different approaches and algorithms exist in that regard (Aggarwal and Zhai, 2012) mostly with the aim of discovering new, previously unknown information (Gupta and Lehal, 2009). In the study at hand, a frequency-driven approach was chosen and applied to the body of documents. This approach can generally be described as contextually simple, it does, however, still yield a reasonable performance (Nenkova and McKeown, 2012). In more detail, the 173 identified media articles were 
JMTM 32,9

80

analyzed in the programming language "R" following the guidance of Popescu and Altmann (2009). The subsequent steps were conducted after combining all media articles into a text corpus; first, the text corpus was converted to lower case letters, and all punctuation was removed. After that, stop words (e.g. "and", "or"), single letters, single numbers and white space were eliminated. Then a limited stemming process was performed upon which key words that belong together were combined (e.g. "face" and "shield" to "faceshield"). The preliminary results were then scanned for futile terms (e.g. "also", "many", "one") that were also removed in order to refine the results. The final word frequency table was analyzed concerning content and dimensions for the subsequent coding process were derived. In order to provide an initial understanding of the text content the word cloud visualization approach was chosen. Word clouds are a visual interpretation of words from a text corpus based on their frequency (Jayashankar and Sridaran, 2017). Even though their ostensible deficiencies in regard to scientific data representation remain (Hearst et al., 2019), they are a widely used tool to provide an intuitive way of visualizing the results of a frequency-based text mining process (Jin, 2017).

\subsection{Development of coding framework}

Seuring et al. (2005) explain that coding dimensions need to be identified and applied to enable a conclusive analysis of the material under regard. Coding dimensions constitute the key topics relevant to analyze the topic under regard and form the basis for the development of a coding framework to extract relevant details on different levels in a structured manner (Tranfield et al., 2003). For the development of the coding framework in our study, we initially identified theoretical (theory-driven) and then contextual groups of dimensions (data-driven) that are relevant for an in-depth analysis of the topic (DeCuir-Gunby et al., 2011). The first theoretical group of dimensions ("AM Technology") concerns the respective technological AM approach used for manufacturing the product under regard. For this purpose, the seven well-established process categories by Gibson et al. (2015) were taken into account. This or similar classifications have already been widely used in scientific research about AM (Wang et al., 2016; Eyers and Potter, 2017; Garmulewicz et al., 2018; Kellens et al., 2017). The second theoretical group describes the "Product Category", indicating what kind of general purpose the product serves. In this regard, frameworks developed by Attaran (2017), Durach et al. (2017) and Schniederjans (2017b) were combined and condensed to result in the categories as listed in Table 2. The third theoretical group ("Design Type") is binary, and it describes whether the product designs are proprietary or shared openly with other potential participants. Chan et al. (2018) as well as Laplume et al. (2016) have explained that openly sharing design files, often through open-source platforms, is common practice in the AM domain.

While the theoretical groups of dimensions are more general, the contextual groups of dimensions are specific to the topic under investigation. The first contextual group is the type of organization that applied AM during the COVID-19 response. Here "Community", "Company" and "Academic" (i.e. universities and schools) were used, as identified during the initial text mining step. The second contextual group includes the actual products manufactured, where the different products were assigned to common product types found among the initiatives. These product types as well as industry sectors were established on a rolling basis while analyzing the material under regard. In addition, the scale concerning the number of pieces made and the locations where the printing activity was performed on a country level were assessed. 


\begin{tabular}{|c|c|c|c|}
\hline Groups & Dimensions & Identification method & Global AM \\
\hline AM technology & $\begin{array}{l}\text { Vat photopolymerization / powder bed fusion / } \\
\text { material extrusion / material jetting / binder jetting / } \\
\text { sheet lamination / directed energy deposition }\end{array}$ & Theory-driven & COVID-19 \\
\hline $\begin{array}{l}\text { Product } \\
\text { category }\end{array}$ & $\begin{array}{l}\text { Prototype / finished good / spare part / enhancement } \\
\text { part / component part / machine tool / repair }\end{array}$ & Theory-driven & \\
\hline Design type & Own design / shared design & Theory-driven & 81 \\
\hline $\begin{array}{l}\text { Organization } \\
\text { type }\end{array}$ & Community / company / academic & Data-driven (text mining) & \\
\hline Product & E.g. ventilator, face shield etc. & $\begin{array}{l}\text { Data-driven (deduced through } \\
\text { systematic review on rolling } \\
\text { basis) }\end{array}$ & \\
\hline Industry & E.g. medical, industrial etc. & $\begin{array}{l}\text { Data-driven (deduced through } \\
\text { systematic review on rolling } \\
\text { basis) }\end{array}$ & $\begin{array}{r}\text { Table } 2 . \\
\text { Coding framework as }\end{array}$ \\
\hline Scale & $<500 / 501-10,000 />10,000$ pieces produced & Predefined & identified for product \\
\hline Location & All identified countries & Predefined & \\
\hline
\end{tabular}

\subsection{Data coding}

After the compilation of the non-exhaustive product list, the collected data regarding AM products was manually coded following the coding framework. This was performed in Excel following the example of Aurini et al. (2016). From a methodological viewpoint, a code is a piece of information commonly embodied in textual or visual data (Saldaña, 2015). In more practical terms this means that the authors assigned information from the secondary data sources to the above defined coding dimensions, which then constitutes a code. As the coding process is qualitative in nature, it should be performed by two researchers independently to reduce the subjectivity bias and increase the reliability of the generated results (Rutter et al., 2010; Seuring et al., 2005). Therefore, the coding was performed by both authors independently and afterward the Cohen's Kappa $(\kappa)$, which is the standard metric to assess intercoder reliability, was calculated (Seuring and Gold, 2012; Lombard et al., 2002). A $\kappa=0.785$ was achieved, which indicates a substantial intercoder reliability, according to Landis and Koch (1977). After the independent coding of the data, remaining coding inconsistencies were jointly assessed, and the corresponding source material was reexamined to arrive at the final coding results analyzed and discussed in the subsequent sections of this article.

\section{Results}

In the following section, the results of the systematic review are presented. The first set of results is derived from the text mining and then the results from the coding process are analyzed based on descriptive explorations.

\subsection{Text mining results}

To gain an initial understanding of the global AM actions in the COVID-19 response, we explored the topic from a meta-perspective to reveal essential elements and trends in this regard. In doing so, we applied frequency-based text mining to analyze relevant documents and press releases.

The word cloud in Figure 2 summarizes the results of the text mining process by highlighting the key topics in relation to AM and its role during the COVID-19 pandemic corresponding to word frequency. The identification of terms such as "3dprinting" and "covid19" as well as "production", "printing" and "manufacturing" as highly important is obvious, but several other aspects are more informative. The prominence of the word 
JMTM 32,9

\section{2}

Figure 2.

Word cloud of the most prevalent terms in analyzed online media sources

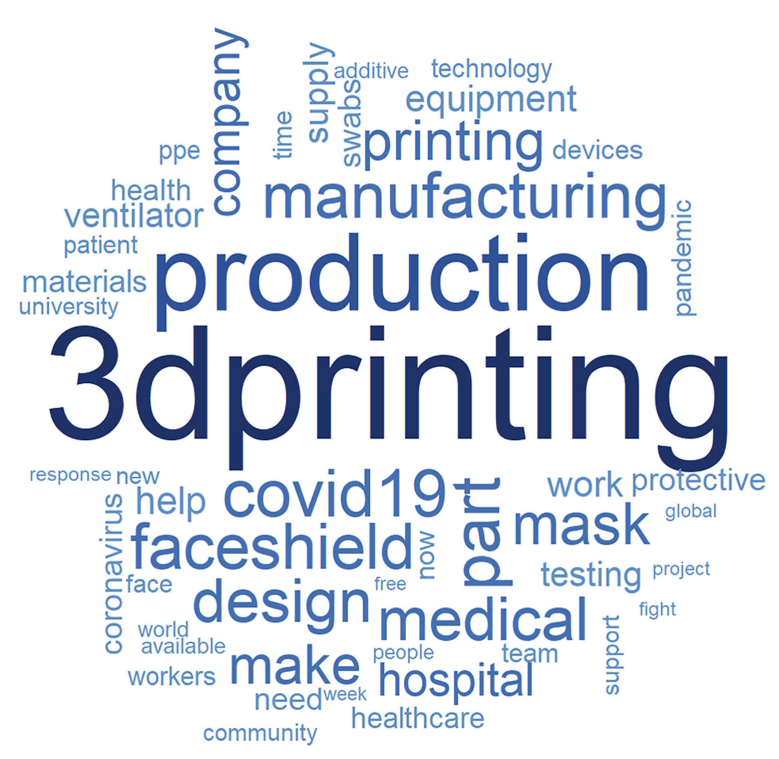

"medical" and related terms including "healthcare", "hospital", "patient", "health" and the like already point toward the overall focus of the AM response during the COVID-19 pandemic, namely the medical domain. Within that realm, the manufacturing of PPE ("ppe") such as "faceshield" or "mask" and the manufacturing of other necessary "equipment" like "ventilator" or "swabs" appear to be the key issues for AM usage during the COVID-19 crisis. Additionally, we can also see which parties were most active in this endeavor, as "company", "community" and "university" seemed to be involved alike. Finally, the importance of "help", "support" and "need" indicates that the AM action was much desired.

\subsection{Coding results}

The identified AM initiatives span from simple community-based desktop printing to largescale industrial operations. The first interesting learning from this investigation pertained to the vast global distribution of AM efforts in the fight against COVID-19. As can be seen in Figure 3, AM activities could be identified in all inhabited continents; including initiatives from a total number of 115 different countries (countries in gray had no products on the nonexhaustive list).

Another learning that became immediately apparent is that the majority $(90.3 \%)$ of the products under regard could be associated with the medical domain. This is understandable, as the COVID-19 pandemic was a health-related crisis and there were dire shortages in necessary equipment. This observation is supported by Fontana et al. (2019) and Muir and Haddud (2017), who have already shown in previous application cases that AM can be highly beneficial in the medical domain. In this regard, the focus of the AM community was on providing desperately needed PPE. In almost half of all the cases (45.7\%), face shields were produced. These face shields are transparent frames that are fixed to a clip that is then attached to the bearer's head or, alternatively, caps or even helmets. They reduce the excessive distribution of bodily fluids exhaled through facial cavities and have the advantage of not impairing free breathing, as is the case with face masks. The second most prominent 
product were parts for ventilators $(15.6 \%)$, whereas here it is important to distinguish between different types of parts. Of the 45 times ventilator-associated AM was recorded, 19 were component parts (i.e. actual working parts of a ventilator); 15 were enhancement parts (e.g. airflow splitters that allow the parallel treatment of two or more patients with a single machine); 6 were prototypes, and 5 were spare parts (e.g. replacement valves). Shortages of these intensive care instruments used to facilitate the breathing of COVID-19 patients were found to be common in some areas. Facemasks were the third largest product group $(10.7 \%)$, for which a wide array of applications was created. Most of them rely on a textile-based filter inlet to be inserted before final use. In several cases, mask adjusters (4.8\%), which can reduce the strain on the bearer's ears when wearing regular masks, were also printed. Nasal swabs used for test taking $(3.8 \%)$ are another medical good where shortages were particularly severe and that were hence additively manufactured through vat photopolymerization. Several other notable yet specialized medical products were also made with AM. Prellis Biologics (2020), a bio-tech startup, bio-printed synthetic lymph nodes to support virologists during antibody and vaccine research. Formlabs (2020b) in cooperation with other companies and researchers developed a so-called rapid diagnostics kit with the goal of speeding up the diagnosis of COVID-19 in infected patients. They designed an affordable yet highly reliable test-kit that can be manufactured using a stereolithography AM machine. The University of Southern Denmark (2020) developed a fully automatic robot for COVID-19 viral test swabs that is partially manufactured with AM. Creatz3D (2020) additively manufactured manikins from medical scanning data to enable training for respiratory swab collection. Additionally, snorkel mask adapters for ventilation connection, safety goggles and intubation equipment also have to be mentioned as medical goods.

With respect to the production of non-medical items, hands-free door handles $(4.8 \%)$ were in the focus of AM operators. Many different designs were used, such as handheld devices, foot-operated openers, or openers that are fixed to the door itself. Besides, several other and more specialized initiatives could also be identified. For instance, Winsun (2020), an innovative Chinese construction company, 3D-printed isolation homes and smart temperature-measuring disinfection checks that can serve to support hospitals and

\section{Global Distribution of identified Products}

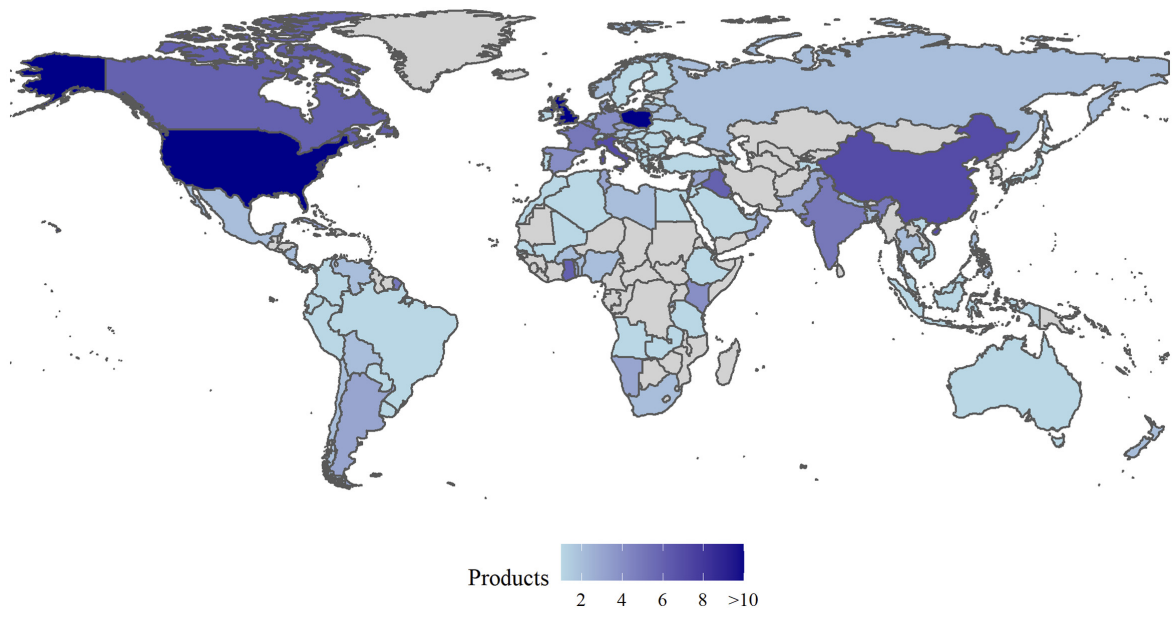

Global AM response to COVID-19
Figure 3.

Global distribution of the 289 identified AM products during the COVID-19 response 
JMTM 32,9

\section{4}

healthcare operators, especially in densely populated areas. In Australia, SPEE3D (2020) additively manufactured appliances using a specialized metallic copper coating for antimicrobial surfaces. Additional interesting initiatives include AM prototyping for disinfection robots and air purifiers as well as the creation of foot-operated washbasins and other hands-free household appliances. Four companies also offered to print industrial parts at reduced prices or even free of charge if the recipient was a company facing supply shortages due to the COVID-19 pandemic.

After explaining which products were additively manufactured in general, we now take a closer look at which AM technologies were used to create which category of products (in the following all evaluations are for 285 products, as in 4 cases only general support was explicitly offered). Figure 4 presents a graphical depiction of a contingency table contrasting the product category dimensions with the applied AM technologies. Here it becomes obvious that the vast majority of the products were made with material extrusion $(79.6 \%)$, which is not surprising as this is the most common and accessible AM technology. In more detail, more than half of all products $(56.1 \%)$ were component parts manufactured using material extrusion. This technology was also the predominant solution for the other product categories. Other AM technologies that were used in more than just a few cases are vat photopolymerization $(9.5 \%)$, mostly for the production of nasal swabs and powder bed fusion $(8.1 \%)$. Material jetting, direct energy deposition and binder jetting were sparsely used, and no products manufactured using sheet lamination techniques were identified. Concerning the product category, it can be seen that $65.6 \%$ of all products were components of a more complex article. The most prominent example of this are face shields, where the frame can be manufactured using AM, but the transparent visor and the head strap are made using other approaches such as, for example, laser cutting. These separate parts are then assembled to make the finished face shield. Similarly, $8.8 \%$ of all products were enhancement parts for existing goods, such as, for example, added airflow splitters for ventilators or additional filters for scuba masks. Furthermore, $4.2 \%$ of the products were used for prototyping (e.g. novel developments for ventilators) and $2.1 \%$ were used as spare parts (e.g. ventilator replacement parts). One in five $(19.3 \%$ ) of all products were assigned to the finished goods category, where the additively manufactured product was directly applicable without further assembly operations (e.g. hands-free door handles).

Figure 4.

Contingency plot of $\mathrm{AM}$ product categories and the corresponding AM technology used in response to COVID-19

\section{Product Category and AM Technology}

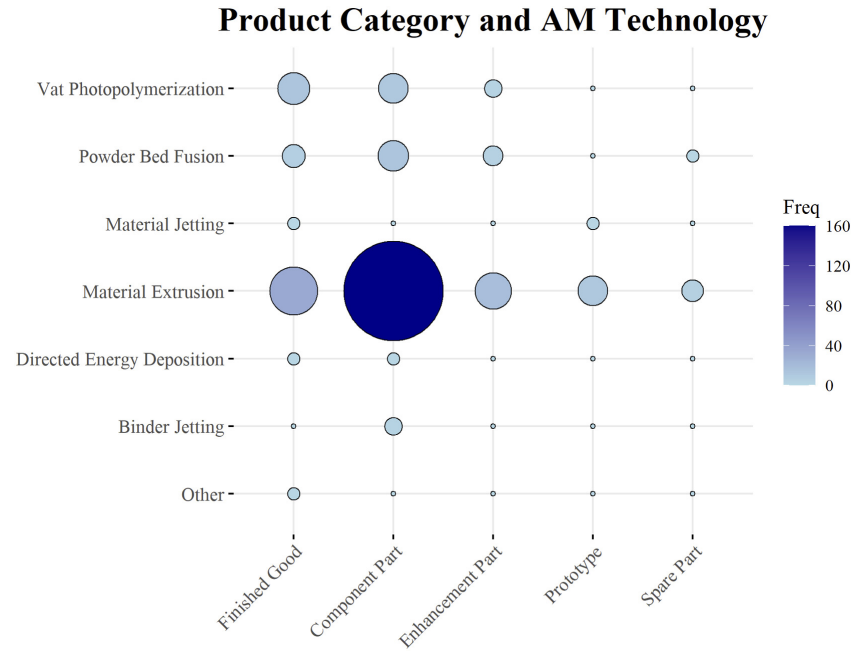


Figure 5 provides a summary of the dimensional distribution of the identified AM products. On the $y$-axis, the three organization types are shown. Companies ( $42.8 \%$ of total) and community-based initiatives $(41.8 \%)$ were found to be equally active. Additionally, $15.4 \%$ of all products were made by academic institutions such as universities or schools. From that distribution, it can be deduced that companies were among the key drivers of AM in response to COVID-19, especially given the observation that many community-based initiatives also involved professional companies; non-commercial organizations can however not be neglected. On the $x$-axis material extrusion and other AM technologies are compared. An interesting observation in that regard is that $74.1 \%$ of all products made with other technological AM solutions than material extrusion were produced by companies. This might be explicable by the fact that these technologies are more advanced and require higher investments as well as organizational knowledge than simple desktop 3D printers. Finally, Figure 5 also includes two facets distinguishing whether a shared design or a proprietary "own" design was used. The majority $(68.4 \%)$ of all products made were based on shared designs made available publicly on the Internet. Here again, it can be seen, however, that companies reacted a bit differently to communities and academic institutions. Two-thirds $(66.7 \%)$ of all products based on own designs were made by companies, which can possibly also be attributed to a higher knowledge base available in professional AM environments. To look more carefully at the different dimensional distribution between products based on shared or own designs, chi square $\left(\chi^{2}\right)$ tests were conducted, contrasting organization type and AM tech for both design types (i.e. the two facets shown in Figure 5). In the case of own design $\left(\chi^{2}=2.58\right.$ at $\left.\mathrm{df}=2\right)$ a $p$-value $=0.28$ was computed, while for shared design $\left(\chi^{2}=21.61\right.$ at $\left.\mathrm{df}=2\right)$ a $p$-value $<0.001$ was reached. This means that there is no significant relationship between AM techs and organization types for own designs, but for shared designs a significant dependence between AM techs and organization types can be identified. Deducing from this, we can say that for shared designs the various organizations certainly apply material extrusion preferentially compared to other technological alternatives.

\section{Product Distribution}

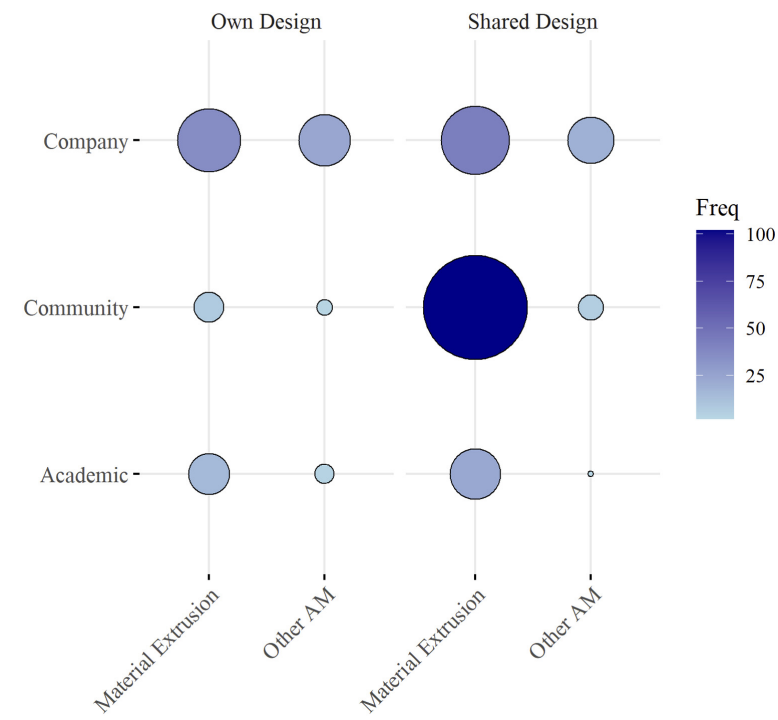

Figure 5. Contingency plot of AM products made in response to COVID-19 corresponding to coding dimensions 
JMTM

32,9

86

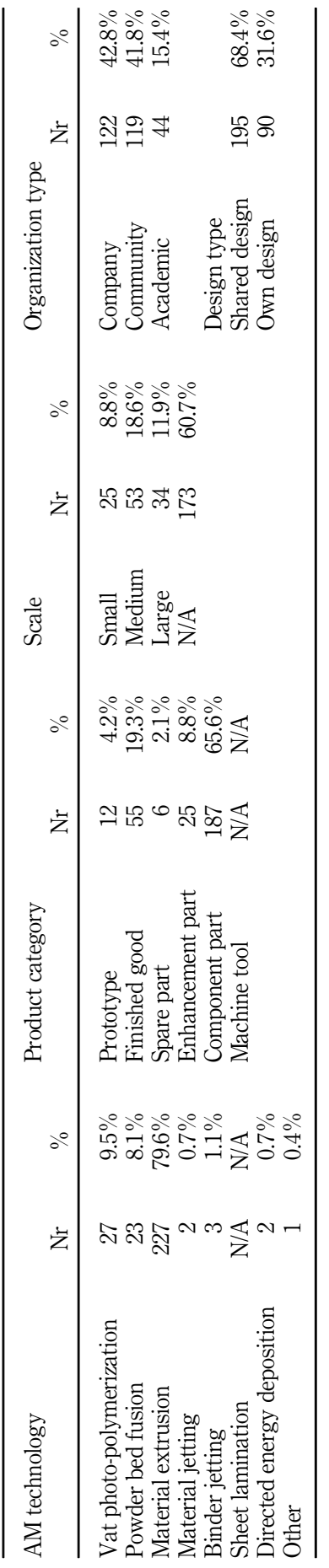

Table 3.

Dimensional

association of AM

products for COVID-19

response compared to grand total 
A conclusive account of the dimensional associations of AM products for COVID-19 response is shown in Table 3. The final classification dimension evaluated during the systematic review is the scale of the initiative expressed through the number of products made. Here, the study differentiated between small-, medium- and large-scale production. In this regard, it has to be noted, however, that information concerning the scale was not attainable in many cases and hence absolute comparisons cannot be drawn. Nevertheless, the observation that 34 products were manufactured on a large scale ( $>10,000$ products made) is astonishing and will be further discussed in the following section. Additionally, 53 products were made on a medium scale $(501-10,000)$.

\section{Discussion}

In the following section, several key learnings regarding the AM response to the COVID-19 pandemic as well as the AM industry in general are presented. We first discuss novel and manifested benefits and prospects of AM, after which we also regard new and remaining challenges. The identified issues are analyzed by briefly elaborating on the existing scientific perception concerning AM, which we then contrast to - and expand by - the findings generated by the above-presented analysis. From this comparison, we deduce novel insights with a focus on related implications for policy-makers and practitioners.

\subsection{Additive manufacturing management prospects}

The vast amount of different initiatives and the huge global response of AM to the COVID-19 pandemic led to several implications regarding AM and associated management activities. In the following, we explain where new AM benefits and prospects emerged and where existing ones were notably reinforced or manifested themselves through new applications.

5.1.1 Mass production with additive manufacturing. In the early days of AM, this novel manufacturing approach was commonly called "rapid prototyping" (Gibson, 2017). Prototypes are one-offs and are generally produced under lower quality and reliability standards when compared to finished goods. This stigma and the concerns about manufacturing efficiency (Fawcett and Waller, 2014) stayed with AM, but the impressive global action by the AM community during the COVID-19 pandemic has the potential to alter this perception.

In this study, we identified 34 products that were produced on a large scale. Several companies and organizations were able to mass-produce desperately needed goods, as conventional manufacturing and sourcing modes faltered during the pandemic. Among the most sought-after medical goods were viral tests and associated testing equipment, as testing people was a critical containment measure against the spread of COVID-19. This, however, was limited by testing capacity and equipment availability. One item type with a particularly large demand-supply gap were the test swabs for the collection of viral samples. These flexible sticks with a bristled end are inserted into the nose or mouth of a patient to collect traces of the virus that can later be analyzed in a laboratory. With swab supplies running short in the US, Formlabs (2020a) stepped up to produce over 100,000 such COVID-19 test swabs, daily. Another US.-based medical manufacturing company, Resolution Medical (2020), reportedly scaled up its nasal swab production capacity to one million per week by means of AM, while Envisiontec (2020) announced that it can produce up to one million per day through their own manufacturing capacity and partner network. Another area where shortages were common during the pandemic is PPE. The so-called face shield coalition, initiated by Stratasys (2020), was able to ship over 275,000 face shields in just around two months throughout the US. This coalition involved professional fabrication labs and other types of companies and colleges who participated in this effort. Hewlett Packard, in cooperation with its partners, reportedly printed 200,000 of these face shields and over a million parts for protection equipment in total. 
JMTM 32,9

Test swabs and face shield frames are rather simple products but the above-mentioned initiatives still indicate that AM has taken a further step in its transition toward being a viable manufacturing approach, even for the purpose of mass production. Especially, as according to Deradjat and Minshall (2017), AM mass production in the medical domain has in a few cases already occurred before. In this context, several pressing implications of AM further emerge; most importantly, the potential restructuring of global manufacturing distribution as previously outlined by Hannibal and Knight (2018). With AM, production can shift away from established traditional manufacturing bases, closer to the point of need, a feature that was of particular importance for overcoming supply shortages during the COVID-19 pandemic. As a result, industries will have to adopt concerning transportation networks, supply chain structure, work force composition and the like. This, inevitably, also calls for related policies, where the main identified shortcoming was a missing public awareness of mass manufacturing capabilities of AM. Involved public institutions-such as public health services-were not fully aware of AM capabilities and are required to fathom this novel development.

5.1.2 Applied manufacturing flexibility. The manufacturing flexibility of AM has been hailed for many years, stemming from the fact that products are made layer by layer directly from computer-aided design files with little human intervention (Eyers et al., 2018; Weller et al., 2015). For this reason, AM machines increased in popularity and were installed in many workshops and businesses around the globe (Boon and van Wee, 2018).

During the COVID-19 pandemic and associated disruptions, this manufacturing flexibility proved to be an invaluable asset, especially in terms of PPE supply chains. The speed and agility with which many AM organizations were able to supply novel products was astonishing. Josef Prùša, a pioneer in the realm of affordable AM machine production, announced that it took his company only three days to shift to the mass production $(>200,000$ pieces) of face shields (Prusa, 2020). This indicates that within a matter of days, his company was able to mass-produce goods it had never produced before, for a market it had never plied before. In the same vein, another impressive example is the automotive industry that has, in many cases, shifted gears not to produce cars but rather to focus on manufacturing medical goods. Several well-known car manufacturers joined the manufacturing response to the COVID-19 pandemic. Škoda (2020), for example, has built over 240,000 respirators and face masks with its AM capabilities. Further, Volkswagen and SEAT have collaboratively designed their own ventilator model (Volkswagen, 2020). Even Ferrari (2020), the Italian luxury sports car manufacturer, started printing respirator valves and fittings for protective masks in an effort to support the heavily strained Italian healthcare sector in the fight against COVID-19.

While the general idea concerning the flexibility of AM is not new, the application of this well-known strength of AM during the COVID-19 pandemic presented a valuable practical example. With the manufacturing flexibility achieved, the first demand and supply shocks of medical goods were alleviated. This means that, while traditional manufacturing installations required time to change over their production lines, AM jumped in and buffered the negative impacts of product shortages. For practitioners this indicates that looking beyond their traditional manufacturing scope becomes increasingly interesting, as a manufacturing diversification into other fields was shown to be possible within a short period of time. Additionally, this capability also proved to be a valuable asset for involved policymakers (e.g. government institutions concerned with emergency supply), and they should strive to include AM capabilities in their future contingency plans.

5.1.3 Applied collaborative manufacturing. The envisioned manufacturing layout of global - yet decentralized and locally connected - AM networks with an agile (mass) manufacturing capacity has so far attracted a lot of scientific interest (Rehnberg and Ponte, 2018; Holzmann et al., 2017; Kleer and Piller, 2019). Birtchnell and Urry (2013) even laid out a scenario in which AM community-based manufacturing will play an essential role in the future manufacturing 
landscape. The feasibility of such a concept and whether it is really capable of meeting market demands has, however, remained questionable.

In this regard, the COVID-19 pandemic presented an opportunity for the AM community to substantiate the potential of collaborative manufacturing. As we found in our study, almost $42 \%$ of the identified products were manufactured on a community level rather than by specialized manufacturing companies alone. The Stratasys face shield coalition was, as already explained, able to mass-produce face shields. This, however, was achieved by relying on a network of different manufacturers rather than a centralized manufacturing plant (Stratasys, 2020). Similarly, Siemens (2020) launched initiatives through its AM network to quickly respond to requests from doctors, hospitals and medical equipment suppliers. A different collaborative approach was led by the America Makes (2020) community of AM professionals that launched various contests such as the Fit to Face-Mask Design Challenge and the COVID-19 Makers Challenge. These challenges led to the development of innovative solutions for problems faced by first responders and healthcare personnel. At a more regional collaboration level, Make4Covid (2020), for instance, was able to deliver over 40,000 pieces of PPE to local health agencies in less than two months by partnering with more than a hundred organizations and over 2,000 community volunteers. Elsewhere in the world, similar movements arose, such as the Turkish 3Boyutlu Destek (2020) community, which includes over 3,000 participants and was able to deliver more than 100,000 face shields to institutions in the entire country. In Brazil, a formation known as SOS3D COVID19 (2020) managed the provision of more than 23,000 face shields, often with the support of private makers.

From a practical point of view, the major learning was that community-based collaborative AM initiatives were realized by relying on an iterative process. Design files were created and shared online; users then downloaded them, printed the necessary product and occasionally improved the original design, which was then often shared again. In this way, AM was able to satisfy demand at the point of need with little time delay. Thus, it can be said that during the COVID-19 pandemic, the decentralized collaborative manufacturing layout proved that it could perform as envisioned and provide great value to the manufacturing domain and society. For policymakers this approach calls for future participation. In the case of America Makes, several United States government agencies got involved at various stages of the described process during the COVID-19 pandemic. This included capacity coordination, demand communication, design testing and so forth. To better harness collaborative community AM in the future, the long-term establishment of private-public cooperation in that regard can be recommended.

5.1.4 Intellectual property. Intellectual property right problems were a frequently recurring issue when discussing inhibiting factors for widespread AM implementation (Chan et al., 2018). Given that original equipment manufacturers have concerns regarding the illegal replication of their original products by third parties, the need for implementing adequate means to protect 3D-printed spare parts is obvious (Chekurov et al., 2018). Taking control over the illegal and undesired distribution of design files via open source platforms is a rather complex process that policymakers and legislators have been facing continuously (Kietzmann et al., 2015).

During the COVID-19 pandemic, several intellectual property issues were also reported, especially in relation to rapidly printed replacement parts for critical equipment (e.g. ventilators), as it was difficult to obtain official approvals from the original equipment manufacturers. In regard to those issues, Gibson (2017), Shukla et al. (2018) and Chekurov et al. (2018) have already pointed out that sharing designs in the community can help alleviate related problems. This proved to be true during the COVID-19 response, were we found that more than $68 \%$ of all products made were based on shared designs. Several initiatives even reported that it was easier to get government approvals for a shared design if that design had already been approved by other governments or companies elsewhere in the world. Also, recommendations published by industry actors (e.g. European Association of the Machine 
JMTM 32,9
Tool Industries and related manufacturing technologies) on how to further proceed in COVID-19 related items production without violating intellectual property helped to relax the situation (Mahr and Dickel, 2020). At the same time, several leading companies that own relevant intellectual property have committed to providing (temporary) open licenses to their proprietary intellectual property at no cost/royalty-free trough the publicly available platform Open Covid Pledge (2020). This should further lower the risk of intellectual property infringement liability for providers of 3D image files and AM machines.

Despite the situations' criticality, having adequate policies at hand is crucial for ensuring certain quality standards of produced goods, which in most cases served life-protecting measures (e.g. respiratory valves, etc.) during the acute phase in the COVID-19 pandemic. As can be seen from first attempts by above-mentioned organizations, a harmonization of intellectual property on a global scale is gaining momentum. Policymakers are advised to continue debating with entrepreneurs, inventors, trademark attorneys and to jointly elaborate on standards for intellectual property rights, including copyrights, patents and design rights. In this regard, the European Patent Office and the European Union Intellectual Property Office have already realized the need for collaborative interventions and therefore have recently initiated digital conferences that offer the required means of communication.

5.1.5 Standards and certifications. Up to now, lacking industry standards (Hannibal and Knight, 2018; Khorram Niaki and Nonino, 2017; Scott and Harrison, 2015) and challenging product certification processes (Ballardini et al., 2018; Knofius et al., 2016) were frequently recurring issues when discussing inhibiting factors for widespread AM implementation.

Conforming to quality standards remains challenging. As it has already been explained, many initiatives involved the distributed printing of products, which often encompassed professionals and hobbyists alike. The standardization of the products proved difficult, but positive examples can be mentioned. In the case of the 3D-printed nasal test swabs, product tests by federal agencies have shown that these swabs perform as well as or better than traditionally-manufactured swabs (Formlabs, 2020a). Concerning the related process of product certification, a trend that became apparent during the COVID-19 pandemic was that many government bodies issued special guidance for immediate response manufacturing, such as the US Food and Drug Administration (2020) (FDA) and the European Commission (2020), or generally lowered their certification standards because shortages were too dire. In their efforts, the FDA followed a risk-based approach that allows the relaxation of several enforcement requirements to facilitate the use of AM products and to expand availability of desperately needed items. Additionally, a FAQ document was published that provides manufacturers with important information on FDA's Quality System regulations (FDA, 2020). This repeatedly enabled AM companies to obtain emergency clearances for their products under compliance of given quality standards and regulations.

With the interventions by the FDA and others, manufacturers were being offered the opportunity to produce AM materials under approved standards and accepted quality. Following the FDA's approach, policymakers around the globe were directed to frame new policies on standards and certification into existing quality assurance and control systems in order to be better prepared for possible COVID-19 triggered supply shortages. This may also include the cooperation of policymakers and medical device manufacturers to provide proper disclaimers and labeling for AM goods (such as water signs) and to actively communicate those changes in regulations to the broader $\mathrm{AM}$ community. Practitioners on the other hand are asked to raise their awareness for the importance of adequate AM product standardization, in particular for medical purposes at intensive care units and hospitals. Alike with intellectual property, further developments are a matter of intensified collaboration between all involved stakeholders (e.g. policymakers, manufacturers, international standard-setting bodies, etc.) to produce safe, highquality and risk-less materials and goods with the support of AM enthusiasts. 
As impressive as the global response of the AM community in the light of the COVID-19 pandemic was, several well-known shortcomings of this manufacturing approach did however, remain. Additionally, some new and up to now little reported issues also emerged.

5.2.1 Limits of the technological capabilities. Even though the technological capabilities of $\mathrm{AM}$ are increasing constantly, certain corresponding limitations such as range of material, quality, durability and the like remain (Baumers et al., 2013; Zanoni et al., 2019). While from a manufacturing management side, the manufacturing speed as compared to traditional approaches is a further concern (Durach et al., 2017).

When reflecting on the COVID-19 response by means of AM it can be said that the agile manufacturing of urgently needed medical supplies was an important achievement, but it only applied to a limited range of products. As outlined above, face shields, swabs and ventilator parts were printed on a mass scale, though many other medical supplies were still in short supply. Following the results of this study, most printed products were rather simple plastic parts and only $19 \%$ of all the identified products were finished goods. The vast majority of the products were components $(\sim 66 \%)$ or enhancements $(\sim 9 \%)$ of other, more complex, appliances that cannot yet be manufactured with AM alone.

From a practical aspect, this indicates that sophisticated manufacturing involves much more than just the simple making of products. Design, test, validation, distribution and the like remain challenging tasks that require further development. In this regard, the improvements of multi-material printing capabilities as described by Anzalone et al. (2015) are important, but they are still not sufficiently developed to truly overcome larger supply shortages of more complex goods. Using AM as the sole manufacturing approach is, for now, far from feasible, as the possible application areas remain quite limited. This, however, opens the door for development activities and future research, where both the private and the public sector can be more active. Corresponding investments, especially in hindsight of eventual future crises, need to be explored.

5.2.2 Quality. Quality concerns about additively manufactured goods are one of the major obstacles for AM adoption (Colosimo et al., 2018). Two related issues are the porous structure of some 3D-printed parts and the well-known stair-stepping effect caused by the additive nature of the process (Livesu et al., 2017; Petrovic et al., 2011).

In our analysis, we could see that the main response to the COVID-19 pandemic with AM was in printing medical equipment ( $\sim 90 \%$ of all products), with a special focus on PPE. However, medical and clinical quality standards are very high, for good reason. The cavities created through the stair-stepping effect or the porous structure can potentially provide a microscopic shelter for bacteria or the virus itself, a circumstance that cannot be ignored for critical equipment.

To ensure that AM can ultimately cross the line from producing improvised emergency aid articles to being considered a well-established and safe alternative, further technological developments and enhanced post-processing measures (such as polishing, sealing or coating) are needed. This is especially true in community-based decentralized printing. In the circumstances that were faced during the COVID-19 pandemic, it proved helpful when authorized government bodies supported product safety and quality by releasing certified and tested designs and manufacturing parameters.

5.2.3 Coordination. Due to the decentralized and distributed nature of AM supply chains, coordination is a challenging task, especially in regard to matching AM capacity with product demand (Sher et al., 2018).

In relation to the identified importance of community-based AM initiatives, but also with companies or academic institutions, we identified many different approaches of coordination. Some were rather centrally coordinated, via lead companies or organizations; many however relied on their proprietary homepages for product offering and order placement. Not only is 
JMTM 32,9

92 quality assurance and certification difficult in such an environment, but also the question of how to guarantee the match of supply and demand needs to be addressed.

The development of appropriate coordination strategies during stable times can remove this obstacle in the immediate response to crisis but will remain a challenge as new AM capacities are established at a rapid rate. Both practitioners and policy-makers should seek the communication with larger AM networks and the establishment of relevant partnerships for facilitating effective and efficient coordination (Wankmüller and Reiner, 2020).

5.2.4 Raw material supply. The notion that AM can reduce raw material usage and corresponding inventories due to a more efficient production approach is well established (Kunovjanek and Reiner, 2020). AM raw material supply chains are, however, often dependent on a limited range of suppliers (Mellor et al., 2014) that might be located globally. Several organizations aim to address this circumstance by relying on recycled materials that can be sourced locally to produce goods (Garmulewicz et al., 2018).

As shown during the analysis of the AM response to the COVID-19 pandemic, a significant part of the initiatives took place in a distributed and localized manner. Raw material sourcing for AM in many cases, still relies on centralized suppliers or global supply chains, which in turn are vulnerable to disruption. Material recycling can be a counter-measure to such a disruption, but quarantine measures on some occasions prevented people from sourcing raw materials (i.e. plastic waste) locally.

As new AM raw material supply is impaired, inventory levels for AM must also be disaster resistant. This holds true for industries that, for example, aim to print critical spare parts on demand. Contingency planning on a higher strategic or government level that incorporates $\mathrm{AM}$ as an emergency manufacturing alternative needs to condition their raw material supply to be resistant to supply disruptions. This could be performed by increasing safety stocks or by fostering localized raw material production.

\section{Conclusion}

In this study, we analyzed how AM was used globally in response to the COVID-19 pandemic. A systematic review research approach was applied during which 289 AM products were analyzed. This constituted the foundation of subsequent in-depth analysis. We were able to show that AM proved to be a valuable asset in the case of supply chain disruption, as observed during the COVID-19 crisis. A multitude of important products was manufactured and sometimes tailor-made to customer requirements at the point of need. Mass manufacturing and collaborative community-based approaches in connection with AM were shown to work, and AM can now be considered a true manufacturing alternative. That said, certain restrictions remain, but if the positive trend currently associated with the technology is harnessed after the crisis, some of these might be overcome.

There are several issues that limit this research and that are worth further consideration. First and foremost, the selection of relevant products is highly dependent on the search-strings applied, search engines searched and inclusion criteria set. Consequently, we are fully aware of the fact that our selection process may have ignored some relevant data. Also, the quality of the input data is comparatively low when assessed from a scientific viewpoint. Especially in light of the novelty of the topic and the relatively large sample size of 289 analyzed products, this shortcoming, however, can be regarded to be of minor importance. The coding framework is limited in terms of number and content of applied dimensions but serves the purpose of this study well. It is to be noted that even though the coding process was conducted by two researchers independently according to well-established methodological standards, the qualitative nature of the applied research methodology can still lead to biased results.

The key managerial findings of this study are the identification of the main facets of AM during the COVID-19 pandemic including application area, product type, organizational structure and design type. Remaining and novel shortcomings and prospects can also help to 
guide managers for future AM development. Practitioners are made aware of the flexibility and adaptability that AM provides in situations where traditional supply and manufacturing mechanisms reach their limits. We also raise their awareness to consider AM as a backup strategy for strengthening process robustness and for enhancing organizational resilience in times of crisis. Besides, our findings demonstrate the capability of AM to build communal spirit when the need for fast intervention arises.

From an academic point of view, the main contribution is the initial yet conclusive analysis of a topic that has so far not received a lot of scientific attention. By setting our findings in relation to the already existing body of literature, we were able to reveal insights that have not been communicated before. Furthermore, we contributed to the theoretic foundation of AM research by contrasting well-established frameworks with empirical evidence and henceforth enriched the theoretic knowledge base concerning AM. What's more, our findings can help to put related future research on a sound foundation. In that regard, the analysis of several managerial tasks related to immediate manufacturing response, collaborative planning and financial viability might constitute particularly fruit-full research avenues. Additionally, a comparative analysis of risk awareness and differences of legal practice on an international scale can yield interesting insights into the application of AM during the COVID-19 response.

\section{References}

3 Boyutlu Destek (2020), "Covid-19 ile Mücadeleye Tam Destek", available at: https://3boyutludestek. org/ (accessed 30 June 2020).

Advincula, R.C., Dizon, J.R.C., Chen, Q., Niu, I., Chung, J., Kilpatrick, L. and Newman, R. (2020), "Additive manufacturing for COVID-19: devices, materials, prospects, and challenges", $M R S$ Communications, Vol. 10 No. 3, pp. 413-427.

Agarwal, H., Jain, A., Goyal, K. and Gupta, S. (2020), "Self-designed 3-D printed mask to tackle COVID19”, Global Journal of Researches in Engineering (A), Vol. 20 No. 1, pp. 57-65.

Aggarwal, C.C. and Zhai, C. (2012), "An introduction to text mining", in Aggarwal, C.C. and Zhai, C. (Eds), Mining Text Data, Springer, New York, pp. 1-10.

America Makes (2020), "Fighting COVID-19 with 3D printing", available at: https://www. americamakes.us/statement-on-covid-19/ (accessed 7 May 2020).

Amin, D., Nguyen, N., Roser, S.M. and Abramowicz, S. (2020), "3D printing of face shields during COVID-19 pandemic: a technical note", Journal of Oral and Maxillofacial Surgery Official, Journal of the American Association of Oral and Maxillofacial Surgeons, Vol. 78 No. 8, pp. 1275-1278.

Anzalone, G.C., Wijnen, B. and Pearce, J.M. (2015), "Multi-material additive and subtractive prosumer digital fabrication with a free and open-source convertible delta RepRap 3-D printer", Rapid Prototyping Journal, Vol. 21 No. 5, pp. 506-519.

Attaran, M. (2017), "The rise of 3-D printing: the advantages of additive manufacturing over traditional manufacturing", Business Horizons, Vol. 60 No. 5, pp. 677-688.

Attaran, M. (2020), "3D printing role in filling the critical gap in the medical supply chain during COVID-19 pandemic", American Journal of Industrial and Business Management, Vol. 10 No. 5, pp. 988-1001.

Aurini, J.D., Heath, M. and Howells, S. (2016), The How to of Qualitative Research: Strategies for Executing High Quality Projects, Sage, London.

Ballardini, R.M., Flores Ituarte, I. and Pei, E. (2018), "Printing spare parts through additive manufacturing: legal and digital business challenges", Journal of Manufacturing Technology Management, Vol. 29 No. 6, pp. 958-982.

Baumers, M., Tuck, C., Wildman, R., Ashcroft, I., Rosamond, E. and Hague, R. (2013), "Transparency built-in”, Journal of Industrial Ecology, Vol. 17 No. 3, pp. 418-431. 
JMTM 32,9

94

Belhouideg, S. (2020), "Impact of 3D printed medical equipment on the management of the Covid 19 pandemic", The International Journal of Health Planning and Management, Vol. 35, pp. 1014-1022.

Birtchnell, T. and Urry, J. (2013), “3D, SF and the future”, Futures, Vol. 50, pp. 25-34.

Boon, W. and van Wee, B. (2018), "Influence of 3D printing on transport: a theory and experts judgment based conceptual model”, Transport Reviews, Vol. 38 No. 5, pp. 556-575.

Cavallo, L., Marcianò, A., Cicciù, M. and Oteri, G. (2020), "3D printing beyond dentistry during COVID 19 epidemic: a technical note for producing connectors to breathing devices”, Prosthesis, Vol. 2 No. 2, pp. 46-52.

Chan, H.K., Griffin, J., Lim, J.J., Zeng, F. and Chiu, A.S.F. (2018), "The impact of 3D Printing Technology on the supply chain: manufacturing and legal perspectives", International Journal of Production Economics, Vol. 205, pp. 156-162.

Chekurov, S., Metsä-Kortelainen, S., Salmi, M., Roda, I. and Jussila, A. (2018), "The perceived value of additively manufactured digital spare parts in industry: an empirical investigation", International Journal of Production Economics, Vol. 205, pp. 87-97.

Choong, Y.Y.C., Tan, H.W., Patel, D.C., Choong, W.T.N., Chen, C.-H., Low, H.Y., Tan, M.J., Patel, C.D. and Chua, C.K. (2020), "The global rise of 3D printing during the COVID-19 pandemic", Nature Reviews Materials, Vol. 5, pp. 637-639.

Colosimo, B.M., Huang, Q., Dasgupta, T. and Tsung, F. (2018), "Opportunities and challenges of quality engineering for additive manufacturing", Journal of Quality Technology, Vol. 50 No. 3, pp. 233-252.

Cortes, A.R.G., Galea, K., No-Cortes, J., Sammut, E.J., Alzoubi, E.E. and Attard, N.J. (2020), “Use of free $\mathrm{CAD}$ software for 3D printing individualized face masks based on face scans", International Journal of Computerized Dentistry, Vol. 23 No. 2, pp. 183-189.

Cowton, C.J. (1998), "The use of secondary data in business ethics research", Journal of Business Ethics, Vol. 17 No. 4, pp. 423-434.

Cox, J.L. and Koepsell, S.A. (2020), "3D-Printing to address COVID-19 testing supply shortages", Laboratory Medicine, Vol. 51 No. 4, pp. e45-e46.

Creatz3D (2020), "3D printed medical manikins become effective training aids for respiratory swab collection", available at: https://creatz3d.com.sg/3d-printed-medical-manikins-become-effectivetraining-aids-for-respiratory-swab-collection/\#prettyPhoto (accessed 26 June 2020).

DeCuir-Gunby, J.T., Marshall, P.L. and McCulloch, A.W. (2011), "Developing and using a codebook for the analysis of interview data: an example from a professional development research project", Field Methods, Vol. 23 No. 2, pp. 136-155.

den Boer, J., Lambrechts, W. and Krikke, H. (2020), "Additive manufacturing in military and humanitarian missions: advantages and challenges in the spare parts supply chain", Journal of Cleaner Production, Vol. 257, p. 120301.

Deradjat, D. and Minshall, T. (2017), "Implementation of rapid manufacturing for mass customisation", Journal of Manufacturing Technology Management, Vol. 28 No. 1, pp. 95-121.

Durach, C.F., Kurpjuweit, S. and Wagner, S.M. (2017), "The impact of additive manufacturing on supply chains", International Journal of Physical Distribution and Logistics Management, Vol. 47 No. 10 , pp. 954-971.

Emanuel, E.J., Persad, G., Upshur, R., Thome, B., Parker, M., Glickman, A., Zhang, C., Boyle, C., Smith, M. and Phillips, J.P. (2020), "Fair allocation of scarce medical resources in the time of covid-19", New England Journal of Medicine, Vol. 382 No. 21, pp. 2049-2055.

Envisiontec (2020), "EnvisionTEC to 3D print mass quantities of nasopharyngeal swabs for COVID-19 testing based on successful clinical trial", available at: https://envisiontec.com/envisiontec-to-3dprint-mass-quantities-of-nasopharyngeal-swabs-for-covid-19-testing-based-on-successfulclinical-trial/ (accessed 30 June 2020). 
Erickson, M.M., Richardson, E.S., Hernandez, N.M., Bobbert, D.W., Gall, K. and Fearis, P. (2020), "Helmet modification to PPE with 3D printing during the COVID-19 pandemic at Duke university medical center: a novel technique", The Journal of Arthroplasty, Vol. 35 No. 7, pp. 23-27.

European Commission (2020), "Conformity assessment procedures for 3D printing and 3D printed products to be used in a medical context for COVID-19", available at: https://ec.europa.eu/ docsroom/documents/40562 (accessed 02 December 2020).

Eyers, D.R. and Potter, A.T. (2017), "Industrial Additive Manufacturing: a manufacturing systems perspective", Computers in Industry, Vols 92-93, pp. 208-218.

Eyers, D.R., Potter, A.T., Gosling, J. and Naim, M.M. (2018), "The flexibility of industrial additive manufacturing systems", International Journal of Operations and Production Management, Vol. 38 No. 12, pp. 2313-2343.

Fawcett, S.E. and Waller, M.A. (2014), "Supply Chain Game Changers-Mega, Nano, and Virtual Trends-And Forces That Impede Supply Chain Design (i.e., Building a Winning Team)", Journal of Business Logistics, Vol. 35 No. 3, pp. 157-164.

FDA (2020), “3D printing of medical devices, accessories, components, and parts during the COVID-19 pandemic", available at: https://www.fda.gov/medical-devices/coronavirus-covid-19-andmedical-devices/3d-printing-medical-devices-accessories-components-and-parts-during-covid19-pandemic.

Ferrari (2020), "Ferrari continues its efforts to fight the Covid-19 pandemic", available at: https:// corporate.ferrari.com/en/ferrari-continues-its-efforts-fight-covid-19-pandemic (accessed 30 June 2020).

Flanagan, S.T. and Ballard, D.H. (2020), "3D printed face shields: a community response to the COVID19 global pandemic", Academic Radiology, Vol. 27 No. 6, p. 905.

Fontana, F., Klahn, C. and Meboldt, M. (2019), "Value-driven clustering of industrial additive manufacturing applications", Journal of Manufacturing Technology Management, Vol. 30 No. 2, pp. 366-390.

Ford, J., Goldstein, T., Trahan, S., Neuwirth, A., Tatoris, K. and Decker, S. (2020), "A 3D-printed nasopharyngeal swab for COVID-19 diagnostic testing", 3D printing in medicine, Vol. 6 No. 1, p. 21.

Formlabs (2020a), "3D printed test swabs for COVID-19 testing”, available at: https://formlabs.com/ covid-19-response/covid-test-swabs/ (accessed 7 May 2020).

Formlabs (2020b), "Prototyping rapid diagnostics for COVID-19 with 3D printing", available at: https:/formlabs.com/covid-19-response/covid-19-rapid-diagnostics/ (accessed 22 June 2020).

Garmulewicz, A., Holweg, M., Veldhuis, H. and Yang, A. (2018), "Disruptive technology as an enabler of the circular economy: what potential does 3D printing hold?", California Management Review, Vol. 60 No. 3, pp. 112-132.

Gibson, I., Rosen, D. and Stucker, B. (2015), Additive Manufacturing Technologies: 3D Printing, Rapid Prototyping, and Direct Digital Manufacturing, 2nd ed., Springer, New York, NY.

Gibson, I. (2017), "The changing face of additive manufacturing”, Journal of Manufacturing Technology Management, Vol. 28 No. 1, pp. 10-17.

Gomes, B.d.A., Queiroz, F.L.C., Pereira, P.L.d.O., Barbosa, T.V., Tramontana, M.B., Afonso, F.A.C., Garcia, E.D.S. and Borba, A.M. (2020), "In-house three-dimensional printing workflow for face shield during COVID-19 pandemic", Journal of Craniofacial Surgery, Vol. 31 No. 6, pp. e652-e653.

Gupta, V. and Lehal, G.S. (2009), "A survey of text mining techniques and applications”, Journal of Emerging Technologies in Web Intelligence, Vol. 1 No. 1, pp. 60-76.

Hannibal, M. and Knight, G. (2018), "Additive manufacturing and the global factory: disruptive technologies and the location of international business", International Business Review, Vol. 27 No. 6, pp. 1116-1127. 
JMTM 32,9

Hearst, M., Pedersen, E., Patil, L.P., Lee, E., Laskowski, P. and Franconeri, S. (2019), “An evaluation of semantically grouped word cloud designs", in IEEE Transactions on Visualization and Computer Graphics.

Holzmann, P., Breitenecker, R.J., Soomro, A.A. and Schwarz, E.J. (2017), "User entrepreneur business models in 3D printing", Journal of Manufacturing Technology Management, Vol. 28 No. 1, pp. 75-94.

Holzmann, P., Schwarz, E.J. and Audretsch, D.B. (2020), "Understanding the determinants of novel technology adoption among teachers: the case of 3D printing", The Journal of Technology Transfer, Vol. 45 No. 1, pp. 259-275.

Ishack, S. and Lipner, S.R. (2020), "Applications of 3D printing technology to address COVID-19related supply shortages”, The American Journal of Medicine, Vol. 133 No. 7, pp. 771-773.

Jayashankar, S. and Sridaran, R. (2017), "Superlative model using word cloud for short answers evaluation in eLearning", Education and Information Technologies, Vol. 22 No. 5, pp. 2383-2402.

Jin, Y. (2017), "Development of word cloud generator software based on Python", Procedia Engineering, Vol. 174, pp. 788-792.

Karlsson, C. (Ed.) (2016), in Research Methods for Operations Management, 2nd ed., Routledge, New York.

Kellens, K., Baumers, M., Gutowski, T.G., Flanagan, W., Lifset, R. and Duflou, J.R. (2017), "Environmental dimensions of additive manufacturing: mapping application domains and their environmental implications", Journal of Industrial Ecology, Vol. 21, pp. S49-S68, S1.

Khorram Niaki, M. and Nonino, F. (2017), "Impact of additive manufacturing on business competitiveness: a multiple case study", Journal of Manufacturing Technology Management, Vol. 28 No. 1, pp. 56-74.

Kietzmann, J., Pitt, L. and Berthon, P. (2015), "Disruptions, decisions, and destinations: enter the age of 3-D printing and additive manufacturing”, Business Horizons, Vol. 58 No. 2, pp. 209-215.

Kleer, R. and Piller, F.T. (2019), "Local manufacturing and structural shifts in competition: market dynamics of additive manufacturing", International Journal of Production Economics, Vol. 216, pp. 23-34.

Knofius, N., van der Heijden, M.C. and Zijm, W.H.M. (2016), "Selecting parts for additive manufacturing in service logistics", Journal of Manufacturing Technology Management, Vol. 27 No. 7, pp. 915-931.

Kunovjanek, M. and Reiner, G. (2020), "How will the diffusion of additive manufacturing impact the raw material supply chain process?”, International Journal of Production Research, Vol. 58 No. 5, pp. 1540-1554.

La Torre, N.de, Espinosa, M.M. and Domínguez, M. (2016), "Rapid prototyping in humanitarian aid to manufacture last mile vehicles spare parts: an implementation plan", Human Factors and Ergonomics in Manufacturing and Service Industries, Vol. 26 No. 5, pp. 533-540.

Lai, B.K., Erian, J.L., Pew, S.H. and Eckmann, M.S. (2020), "Emergency open-source three-dimensional printable ventilator circuit splitter and flow regulator during the COVID-19 pandemic", Anesthesiology, Vol. 133 No. 1, pp. 246-248.

Landis, J.R. and Koch, G.G. (1977), "The measurement of observer agreement for categorical data", Biometrics, Vol. 33 No. 1, p. 159.

Laplume, A., Anzalone, G.C. and Pearce, J.M. (2016), "Open-source, self-replicating 3-D printer factory for small-business manufacturing", The International Journal of Advanced Manufacturing Technology, Vol. 85 Nos 1-4, pp. 633-642.

Li, Y., Jia, G., Cheng, Y. and Hu, Y. (2017), “Additive manufacturing technology in spare parts supply chain: a comparative study", International Journal of Production Research, Vol. 55 No. 5, pp. 1498-1515. 
Liu, Y., Gayle, A.A., Wilder-Smith, A. and Rocklöv, J. (2020), "The reproductive number of COVID-19 is higher compared to SARS coronavirus", Journal of Travel Medicine, Vol. 27 No. 2, pp. 1-4.

Livesu, M., Ellero, S., Martìnez, J., Lefebvre, S. and Attene, M. (2017), "From 3D models to 3D prints: an overview of the processing pipeline", Computer Graphics Forum, Vol. 36 No. 2, pp. 537-564.

Lombard, M., Snyder-Duch, J. and Bracken, C.C. (2002), "Content analysis in mass communication: assessment and reporting of intercoder reliability”, Human Communication Research, Vol. 28 No. 4, pp. 587-604.

Lück, T., Seifarth, C., Malauschek, P., Schendel, O. and Nopper, H. (2020), "Ramping-up 3D-printed corona devices - additive manufacturing opposing injection moulding", Transactions on Additive Manufacturing Meets Medicine, Vol. 2 No. 1, pp. N/A.

Mahr, D. and Dickel, S. (2020), "Rethinking intellectual property rights and commons-based peer production in times of crisis: the case of COVID-19 and 3D printed medical devices", Journal of Intellectual Property Law and Practice, Vol. 15 No. 9, pp. 711-717.

Make4Covid (2020), "Colorado health care professionals and frontline personnel don't have the equipment they need. We're making it.", available at: https://make4covid.co/ (accessed 2 December 2020).

Maracaja, L., Blitz, D., Maracaja, D.L.V. and Walker, C.A. (2020), "How 3D printing can prevent spread of COVID-19 among healthcare professionals during times of critical shortage of protective personal equipment", Journal of Cardiothoracic and Vascular Anesthesia, Vol. 34 No. 10, pp. 2847-2849.

Marconi, S., Alaimo, G., Mauri, V., Negrello, E., Cattenone, A., Pietrabissa, A. and Auricchio, F. (2020), "Use of AM technologies to face the Covid-19 emergency", Transactions on Additive Manufacturing Meets Medicine, Vol. 2 No. 1, pp. N/A.

Meglioli, M., Toffoli, A., Macaluso, G.M. and Catros, S. (2020), "3D printing workflows for printing individualized personal protective equipment: an overview", Transactions on Additive Manufacturing Meets Medicine, Vol. 2 No. 1, pp. N/A.

Mellor, S., Hao, L. and Zhang, D. (2014), "Additive manufacturing: a framework for implementation", International Journal of Production Economics, Vol. 149, pp. 194-201.

Muir, M. and Haddud, A. (2017), "Additive manufacturing in the mechanical engineering and medical industries spare parts supply chain”, Journal of Manufacturing Technology Management, Vol. 19 No. 1, p. 117.

Nenkova, A. and McKeown, K. (2012), "A survey of text summarization techniques”, in Aggarwal, C.C. and Zhai, C. (Eds), Mining Text Data, Springer, New York, pp. 43-77.

Open Covid Pledge (2020), "Open covid Pledge", available at: https://opencovidpledge.org/.

Petrovic, V., Vicente Haro Gonzalez, J., Jordá Ferrando, O., Delgado Gordillo, J., Ramón Blasco Puchades, J. and Portolés Griñan, L. (2011), "Additive layered manufacturing: sectors of industrial application shown through case studies", International Journal of Production Research, Vol. 49 No. 4, pp. 1061-1079.

Piasecki, J., Waligora, M. and Dranseika, V. (2018), "Google search as an additional source in systematic reviews”, Science and Engineering Ethics, Vol. 24 No. 2, pp. 809-810.

Popescu, I.-I. and Altmann, G. (2009), Word Frequency Studies, Quantitative Linguistics, Mouton de Gruyter, Berlin, New York, Vol. 64.

Prellis Biologics (2020), "Prellis biologics, Inc. Generates 300 human antibodies that bind the SARSCoV2 virus; pursues development of a treatment and preventative therapy for COVID-19 infection", available at: https://www.prellisbio.com/covid (accessed 22 June 2020).

Prusa, J. (2020), "From design to mass 3D printing of medical shields in three days", available at: https://blog.prusaprinters.org/from-design-to-mass-3d-printing-of-medical-shields-in-three-days/ (accessed 8 May 2020). 
JMTM 32,9

98

Ranney, M.L., Griffeth, V. and Jha, A.K. (2020), "Critical supply shortages - the need for ventilators and personal protective equipment during the covid-19 pandemic", New England Journal of Medicine, Vol. 382 No. 18, p. e41.

Rehnberg, M. and Ponte, S. (2018), "From smiling to smirking? 3D printing, upgrading and the restructuring of global value chains", Global Networks, Vol. 18 No. 1, pp. 57-80.

Resolution Medical (2020), "Lattice swabs", available at: https://www.resolutionmedical.com/ latticeswabs (accessed 8 May 2020).

Ritchie, J., Lewis, J., Nicholls, C.M., Ormston, R. and others (2013), Qualitative Research Practice: A Guide for Social Science Students and Researchers, Sage, London.

Rutter, D., Francis, J., Coren, E. and Fisher, M. (2010), SCIE Systematic Research Reviews: Guidelines, 2nd ed., Social Care Institute for Excellence, London.

Saldaña, J. (2015), The Coding Manual for Qualitative Researchers, Sage, London.

Salmi, M., Akmal, J.S., Pei, E., Wolff, J., Jaribion, A. and Khajavi, S.H. (2020), “3D printing in COVID-19: productivity estimation of the most promising open source solutions in emergency situations", Applied Sciences, Vol. 10 No. 11, p. 4004.

Schniederjans, D.G. (2017a), "Adoption of 3D-printing technologies in manufacturing: a survey analysis", International Journal of Production Economics, Vol. 183, pp. 287-298.

Schniederjans, D.G. (2017b), "Adoption of 3D-printing technologies in manufacturing: a survey analysis", International Journal of Production Economics, Vol. 183, pp. 287-298.

Scott, A. and Harrison, T.P. (2015), "Additive manufacturing in an end-to-end supply chain setting", $3 D$ Printing and Additive Manufacturing, Vol. 2 No. 2, pp. 65-77.

Sedigh, A., Kachooei, A.R., Beredjiklian, P.K., Vaccaro, A.R. and Rivlin, M. (2020), "Safety and efficacy of casting during COVID-19 pandemic: a comparison of the mechanical properties of polymers used for 3D printing to conventional materials used for the generation of orthopaedic orthoses", The Archives of Bone and Joint Surgery, Vol. 8 Covid-19 Special Issue, pp. 281-285.

Seuring, S. and Gold, S. (2012), "Conducting content-analysis based literature reviews in supply chain management”, Supply Chain Management: An International Journal, Vol. 17 No. 5, pp. 544-555.

Seuring, S., Müller, M., Westhaus, M. and Morana, R. (2005), "Conducting a literature review - the example of sustainability in supply chains", in Kotzab, H., Müller, M., Reiner, G. and Seuring, S. (Eds), Research Methodologies in Supply Chain Management: In Collaboration with Magnus Westhaus, Physica-Verlag Heidelberg, Heidelberg, pp. 91-106.

Sher, M.M., Kim, S.-L., Banerjee, A. and Paz, M.T. (2018), "A supply chain coordination mechanism for common items subject to failure in the electronics, defense, and medical industries", International Journal of Production Economics, Vol. 203, pp. 164-173.

Shokrani, A., Loukaides, E.G., Elias, E. and Lunt, A.J.G. (2020), "Exploration of alternative supply chains and distributed manufacturing in response to COVID-19; a case study of medical face shields", Materials and Design, Vol. 192, p. 108749.

Shukla, M., Todorov, I. and Kapletia, D. (2018), "Application of additive manufacturing for mass customisation: understanding the interaction of critical barriers", Production Planning and Control, Vol. 29 No. 10, pp. 814-825.

Siemens (2020), "Connecting 3D print services to fight COVID-19”, available at: https://additivemanufacturing-network.sws.siemens.com/fight-coronavirus/ (accessed 7 May 2020).

Singh, A.K. (2020), "Design and development of face shield by 3D printing for the COVID-19 epidemics", International Journal for Research in Applied Science and Engineering Technology, Vol. 8 No. 6, pp. 380-384.

Sinha, M.S., Bourgeois, F.T. and Sorger, P.K. (2020), "Personal protective equipment for COVID-19: distributed fabrication and additive manufacturing", American Journal of Public Health, Vol. 110 No. 8, pp. 1162-1164. 
Škoda (2020), "ŠKODA AUTO's support in fighting COVID-19 met with high demand", available at: https://www.skoda-storyboard.com/en/press-releases/skoda-autos-support-in-fighting-covid-19met-with-high-demand/.

SOS3D COVID19 (2020), "A Ajuda para vencer o Virus”, available at: https://www.sos3dcovid19.com. br/ (accessed 9 May 2020).

SPEE3D (2020), "3D printing a metallic coating of antimicrobial copper to fight the spread of COVID19", available at: https://www.spee3d.com/activat3d-copper/ (accessed 11 May 2020).

Stratasys (2020), "Stratasys face shield coalition celebrates milestone: 100,000 shields shipped", available at: https://www.stratasys.com/covid-19 (accessed 7 May 2020).

Sun, Y., Mercader, A. and Lueth, T.C. (2020), "Design of 3D-printable nasopharyngeal swabs in Matlab for COVID-19 testing", Transactions on Additive Manufacturing Meets Medicine, Vol. 2 No. 1, pp. N/A.

Swennen, G.R.J., Pottel, L. and Haers, P.E. (2020), "Custom-made 3D-printed face masks in case of pandemic crisis situations with a lack of commercially available FFP2/3 masks", International Journal of Oral and Maxillofacial Surgery, Vol. 49 No. 5, pp. 673-677.

Tatham, P., Loy, J. and Peretti, U. (2015), "Three dimensional printing-a key tool for the humanitarian logistician?", Journal of Humanitarian Logistics and Supply Chain Management, Vol. 5 No. 2, pp. 188-208.

Thomas-Seale, L.E.J., Kirkman-Brown, J.C., Attallah, M.M., Espino, D.M. and Shepherd, D.E.T. (2018), "The barriers to the progression of additive manufacture: perspectives from UK industry", International Journal of Production Economics, Vol. 198, pp. 104-118.

Tranfield, D., Denyer, D. and Smart, P. (2003), "Towards a methodology for developing evidenceinformed management knowledge by means of systematic review", British Journal of Management, Vol. 14 No. 3, pp. 207-222.

US Food and Drug Administration (2020), "COVID-19 Related guidance documents for industry, FDA staff and other stakeholders", available at: https://www.fda.gov/emergency-preparedness-andresponse/coronavirus-disease-2019-covid-19/covid-19-related-guidance-documents-industry-fdastaff-and-other-stakeholders (accessed 30 June 2020).

University of Southern Denmark (2020), "Robot swabs patients' throats for Covid-19", available at: https://www.sdu.dk/en/om_sdu/fakulteterne/teknik/nyt_fra_det_tekniske_fakultet/robot-kanpode-patienter-for-covid-19.

Volkswagen (2020), "From making cars to ventilators", available at: https://www.volkswagenag.com/ en/news/2020/03/cars_to_ventilators.html (accessed 8 May 2020).

Vordos, N., Gkika, D.A., Maliaris, G., Tilkeridis, K.E., Antoniou, A., Bandekas, D.V. and Ch Mitropoulos, A. (2020), "How 3D printing and social media tackles the PPE shortage during Covid - 19 pandemic", Safety Science, Vol. 130, p. 104870.

Wang, Y.-H., Trappey, A., Hwang, S.-J. and Chen, K.-L. (2016), "Develop potential solution to the engineering conflicts of additive manufacturing by using the theory of solution of inventive problems (TRIZ) - the case of material jetting process", Journal of the Chinese Society of Mechanical Engineers, Vol. 37 No. 2, pp. 85-93.

Wankmüller, C. and Reiner, G. (2020), "Coordination, cooperation and collaboration in relief supply chain management", Journal of Business Economics, Vol. 90 No. 2, pp. 239-276.

Weller, C., Kleer, R. and Piller, F.T. (2015), "Economic implications of 3D printing: market structure models in light of additive manufacturing revisited", International Journal of Production Economics, Vol. 164, pp. 43-56.

Westphal, E., Mau, R., Dreier, T. and Seitz, H. (2020), “3D printing of frames for anti-coronavirus face shields using different processes and materials", Transactions on Additive Manufacturing Meets Medicine, Vol. 2 No. 1, pp. N/A.

Winsun (2020), "WINSUN makes global donation of 3D printed isolation houses", available at: www. winsun3d.com/En/News/news_inner/id/547. 
Wohlers (2019), Wohlers Report 2019: 3D Printing and Additive Manufacturing State of the Industry, Wohlers Associates, Fort Collins (Colo.).

Zanoni, S., Ashourpour, M., Bacchetti, A., Zanardini, M. and Perona, M. (2019), "Supply chain implications of additive manufacturing: a holistic synopsis through a collection of case studies", The International Journal of Advanced Manufacturing Technology, Vol. 102, pp. 3325-3340, 9-12.

Zuniga, J.M. and Cortes, A. (2020), "The role of additive manufacturing and antimicrobial polymers in the COVID-19 pandemic", Expert Review of Medical Devices, Vol. 17 No. 6, pp. 477-481.

\section{Corresponding author}

Maximilian Kunovjanek can be contacted at: maximilian.kunovjanek@aau.at

For instructions on how to order reprints of this article, please visit our website: www.emeraldgrouppublishing.com/licensing/reprints.htm Or contact us for further details: permissions@emeraldinsight.com 